\title{
A EDUCAÇÃO BÁSICA E A BASE NACIONAL COMUM CURRICULAR
}

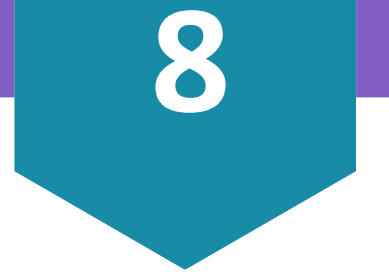

José Genésio Lima da Silva

Especialista em psicopedagogia pela Universidade Estadual do Maranhão - UEMA

Especialista em linguística aplicada pela Faculdade Entre Rios do Piauí - FAERPI Especialista gestão e supervisão escolar pelo Centro de Ensino Superior Múltiplo - CESM Mestrando em Educação pela Universidade Leonardo da Vinci.

\section{RESUMO}

O presente artigo procura dialogar com os preceitos da Base Nacional Comum Curricular em relação com uma educação básica de qualidade. Desta forma, entraremos de uma maneira concisa naquilo que é previsto pelo próprio Governo dentro da BNCC, e o que é adaptado desta para dentro da sala de aula. Assim, também poderemos destacar a importância do que é educar, e como isto é influente dentro de cada instituição de ensino, principalmente, no momento de isolamento social que vivemos atualmente.

Palavras-chave: Base Nacional Comum Curricular; educação básica; sala de aula; educar; aprendizado.

\section{INTRODUÇÃO}

Além de definir os conteúdos que devem ser abordados em cada escola, período ou instituição, a Base Nacional Comum Curricular (BNCC) tornou-se o documento que norteia a gestão no Brasil, sendo um guia para todos os patamares de aprendizagem que todos os brasileiros procuram. $O$ documento da BNCC começou a ser elaborado em 2015, a partir de uma análise profunda realizada por 116 especialistas, num tipo de processo de mobilização das previsões mais importantes dentro do ensino. Nos anos de 2015 e 2016, consultas públicas possibilitaram uma participação direta da população na construção e no estabelecimento de algumas diretrizes, com mais de 12 milhões de solicitações enviadas para o Ministério da Educação (MEC). No final de 2017, todo texto introdutório e as partes referentes à educação foram aprovadas, e em 2018 foi feita a oficialização dos sistemas e redes de ensino que queriam implementar o que era previsto pelo programa.

No contexto de educação, pode-se entender que aquilo que é previsto pelo BNCC abrange desde os planos de aula até a elaboração de uma reflexão da comunidade escolar sobre como é feita a relação de alunoprofessor. De acordo com o Instituto Ayrton Senna (2021), a Base Nacional Comum Curricular é um orientador, usado pelas cidades e estados para 
ajudar a superar toda a fragmentação das políticas educacionais, fortalecendo a colaboração entre as esferas do Governo e a qualidade de educação. Além de orientarem-se pedagogicamente, acontece uma adaptação do trabalho com a escola, como ferramenta de gestão para implementação de políticas públicas.

Naturalmente, a sua implementação prevê muitos desafios, uma vez que a autonomia dos estados e das instituições é algo que deve ser adaptado. Acontece, portanto, uma desconstrução dos discursos hegemônicos e o combate de todas as desigualdades raciais, de gênero e de orientação, trabalhando na recuperação daqueles que são nitidamente excluídos para dentro do ambiente de aprendizado e ensino.

\section{A HISTÓRIA DAS DIRETRIZES CURRICULARES E A BNCC}

A BNCC é um documento sugestivo. Ou seja, ele não impõe, mas ele oferece alternativas. Certamente, não é a primeira vez que as escolas brasileiras se enxergam diante de diretrizes curriculares: entre os anos 1997 e 2000, a Lei de Diretrizes e Bases da Educação Nacional (LDB), assim como os Parâmetros Curriculares Nacionais (PCNs), previam uma divisão e proposta para todos os ensinos básico, fundamental e médio. A LDB 9.394/96 visava, sendo assim:

Art. 1ㅇ A educação abrange os processos formativos que se desenvolvem na vida familiar, na convivência humana, no trabalho, nas instituições de ensino e pesquisa, nos movimentos sociais e organizações da sociedade civil e nas manifestações culturais. $\S 1^{\circ}$ Esta Lei disciplina a educação escolar, que se desenvolve, predominantemente, por meio do ensino, em instituições próprias. $\S 2^{\circ} \mathrm{A}$ educação escolar deverá vincular-se ao mundo do trabalho e à prática social (Lei 9.394, 1996, $\mathrm{s} / \mathrm{p})$.

Sendo assim, a própria educação e o aprender é previsto pelas seguintes normas:

Art. 20 A educação, dever da família e do Estado, inspirada nos princípios de liberdade e nos ideais de solidariedade humana, tem por finalidade o pleno desenvolvimento do educando, seu preparo para o exercício da cidadania e sua qualificação para o trabalho. Art. 3응 $\mathrm{O}$ ensino será ministrado com base nos seguintes princípios: I - igualdade de condições para o acesso e permanência na escola; II - liberdade de aprender, ensinar, pesquisar e divulgar a cultura, o pensamento, a arte e o saber; III - pluralismo de ideias e de concepções pedagógicas; IV - respeito à liberdade e apreço à tolerância; V - coexistência de instituições públicas e privadas de ensino; $\mathrm{VI}$ - gratuidade do ensino público em estabelecimentos oficiais; VII - valorização do profissional 
da educação escolar; VIII - gestão democrática do ensino público, na forma desta Lei e da legislação dos sistemas de ensino; IX - garantia de padrão de qualidade; X valorização da experiência extraescolar; XI - vinculação entre a educação escolar, o trabalho e as práticas sociais. XII - consideração com a diversidade étnico-racial. XIII garantia do direito à educação e à aprendizagem ao longo da vida. XIV - respeito à diversidade humana, linguística, cultural e identitária das pessoas surdas, surdo-cegas e com deficiência auditiva (Lei 9.394, 1997, $s / p)$.

Sendo assim, as próprias leis e normas anteriormente vigentes já prediziam sobre a garantia de um padrão de qualidade de ensino, considerando a diversidade. Os parâmetros curriculares também realizavam o mesmo, destacando a importância de matérias como: língua portuguesa, matemática, ciências naturais, geografia, história, artes, educação física e língua estrangeira. Além disto, estes parâmetros adotam uma postura de valorização da diversidade cultural, do meio ambiente, da saúde e do respeito da orientação sexual. De certa maneira, usá-los dentro do ambiente escolar incide em um ambiente muito mais ordenado, cheio de equidade $e$ apropriação de uma orientação decisiva na organização da sala de aula (MEC, 1997).

Mesmo que antes a questão educativa já fosse muito bem definida, a BNCC, de maneira inovadora, estabeleceu dez competências para nortear cada área de conhecimento, junto com seus componentes curriculares. Segundo o próprio documento, o desenvolvimento dessas competências é essencial para a aprendizagem (MEC, 2018).

\section{A BNCC E O ENSINO BÁSICO}

Segundo o MEC (2018), o documento da BNCC foi estabelecido não somente para alterar um quadro desigual da Educação Básica, mas essencialmente para iniciar uma mudança, além dos currículos, influenciando na formação inicial e continuada dos educadores, e na produção de materiais que sejam, cada vez mais, didáticos. Sendo assim, podemos analisar todas as suas competências para a Educação Básica, que são:

1.Valorizar e utilizar os conhecimentos historicamente construídos sobre o mundo físico, social, cultural e digital para entender e explicar a realidade, continuar aprendendo e colaborar para a construção de uma sociedade justa, democrática e inclusiva. 2. Exercitar a curiosidade intelectual e recorrer à abordagem própria das ciências, incluindo a investigação, a reflexão, a análise crítica, a imaginação e a criatividade, para investigar causas, elaborar e testar hipóteses, formular e resolver problemas e criar soluções (inclusive 
tecnológicas) com base nos conhecimentos das diferentes áreas. 3. Valorizar e fruir as diversas manifestações artísticas e culturais, das locais às mundiais, e também participar de práticas diversificadas da produção artístico-cultural. 4. Utilizar diferentes linguagens - verbal (oral ou visual-motora, como Libras, e escrita), corporal, visual, sonora e digital -, bem como conhecimentos das linguagens artística, matemática e científica, para se expressar e partilhar informações, experiências, ideias e sentimentos em diferentes contextos e produzir sentidos que levem ao entendimento mútuo. 5. Compreender, utilizar e criar tecnologias digitais de informação e comunicação de forma crítica, significativa, reflexiva e ética nas diversas práticas sociais (incluindo as escolares) para se comunicar, acessar e disseminar informações, produzir conhecimentos, resolver problemas e exercer protagonismo e autoria na vida pessoal e coletiva. 6. Valorizar a diversidade de saberes e vivências culturais e apropriar-se de conhecimentos e experiências que lhe possibilitem entender as relações próprias do mundo do trabalho e fazer escolhas alinhadas ao exercício da cidadania e ao seu projeto de vida, com liberdade, autonomia, consciência crítica e responsabilidade. 7. Argumentar com base em fatos, dados e informações confiáveis, para formular, negociar e defender ideias, pontos de vista e decisões comuns que respeitem e promovam os direitos humanos, a consciência socioambiental e o consumo responsável em âmbito local, regional e global, com posicionamento ético em relação ao cuidado de si mesmo, dos outros e do planeta. 8. Conhecer-se, apreciar-se e cuidar de sua saúde física e emocional, compreendendo-se na diversidade humana e reconhecendo suas emoções e as dos outros, com autocrítica e capacidade para lidar com elas. 9. Exercitar a empatia, o diálogo, a resolução de conflitos e a cooperação, fazendo-se respeitar e promovendo o respeito ao outro e aos direitos humanos, com acolhimento e valorização da diversidade de indivíduos e de grupos sociais, seus saberes, identidades, culturas e potencialidades, sem preconceitos de qualquer natureza. 10. Agir pessoal e coletivamente com autonomia, responsabilidade, flexibilidade, resiliência e determinação, tomando decisões com base em princípios éticos, democráticos, inclusivos, sustentáveis e solidários (MEC, 2018, p. 12).

Sendo assim, pode-se, de forma a valorizar este conteúdo, entender que o esforço para aplicar tais competências não é só da instituição de ensino, mas da união de gestores, professores, alunos, famílias e da sociedade, em geral. Todas estas competências e diretrizes buscam, de 
maneira bem salientada, transformar a educação. De maneira resumida, elas remetem muito à conhecimento, pensamento crítico, repertório cultural, comunicação, cultura digital, trabalho, argumentação, autocuidado, empatia e responsabilidade. Tudo isto é diretamente aplicado em um ensino completo, da parte dos professores, para os alunos, com metodologias e técnicas que abordem essa questão mais inovadora, apossando-se do cognitivo e do trabalho corporal para adquirir protagonismo dentro da sua própria produção de sentidos (MEC, 2018).

\section{CONCLUSÃO}

O conceito de competência, adotado pela BNCC, marca uma discussão muito mais pedagógica e social do que aquela que vêm acontecendo nas últimas décadas e tempos. A verdade é que, mesmo com a LDB de 1996 e as PCNs, muitas dúvidas surgem, ainda mais por parte dos educadores e dos que fazem parte do conselho docente, sobre o melhor jeito de adaptar-se para a modernidade dentro da questão de ensinar.

Ao adotar este foco de solucionar todos os problemas, ainda mais por ser um documento que foi criado através de uma discussão feita socialmente, a BNCC indica decisões pedagógicas que possam orientar a constituição de conhecimentos, habilidades, atitudes e valores que devem ser considerados indispensáveis para cada indivíduo.

Conclui-se, portanto, que independentemente do tipo de pessoa, a atual consideração das referências deste documento não assegura somente aquilo que é essencial, que é o aprendizado, mas também um olhar inovador e inclusivo na questão do que deve ser abordado dentro da sala de aula, e o conteúdo que pode fazer diferença na vida de cada estudante.

\section{REFERÊNCIAS BIBLIOGRÁFICAS}

INSTITUTO AYRTON SENNA. 2021. O que é BNCC. Disponível: https://institutoayrtonsenna.org.br/pt-br/BNCC/o-que-e-BNCC.html. Acesso: 20 set. 2021.
Lei
9.394.
1997.
In: Planalto.
Disponível:

http://www.planalto.gov.br/ccivil_03/leis/19394.htm. Acesso: 20 set. 2021.

MEC. 1997. Parâmetros Nacionais Curriculares. Disponível: http://portal.mec.gov.br/seb/arquivos/pdf/livro01.pdf. Acesso: 20 set. 2021.

MEC. 2018. Base Nacional Comum Curricular. Disponível:http://basenacionalcomum.mec.gov.br/images/BNCC_EI_EF_110 518_versaofinal_site.pdf. Acesso: 20 set. 2021. 